\title{
Erratum to: Old money, the nouveaux riches and Brunhilde's marriage strategy
}

\section{The Publisher ${ }^{1}$}

Published online: 20 September 2016

(C) Springer-Verlag Berlin Heidelberg 2016

\section{Erratum to: J Popul Econ \\ DOI 10.1007/s00148-016-0610-3}

The publisher regrets its mistake in switching the captions for Figs. 1 and 2. The corrected versions are below and the original article has been corrected.

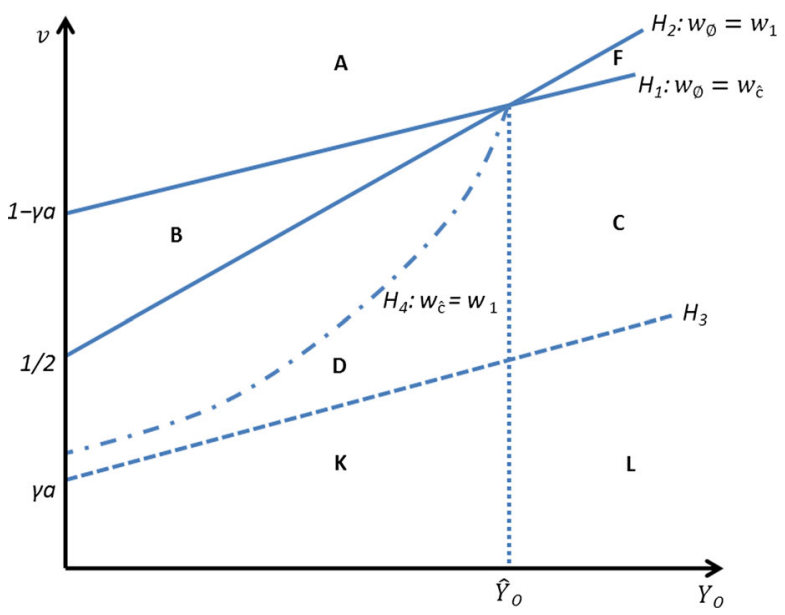

Fig. 1 Brunhilde's strategy for a given $Y_{O}$

The online version of the original article can be found under doi:10.1007/s00148-016-0610-3.

\section{The Publisher}

1 Springer-Verlag Berlin, Heidelberg, Germany 


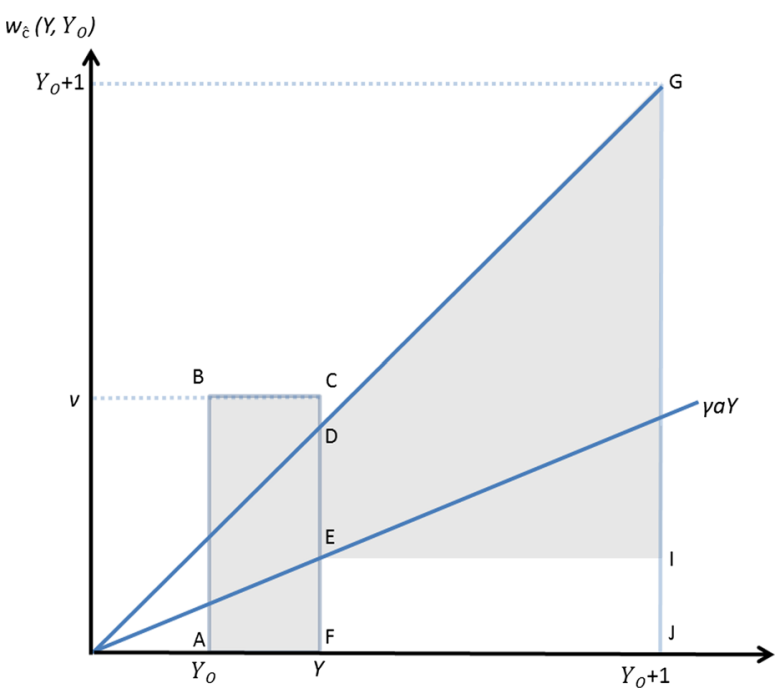

Fig. 2 Brunhilde's payoff for a given $v$ and $Y_{O}$ 